\title{
ANÁLISE DAS MANIFESTAÇÕES PATOLÓGICAS ENCONTRADAS NO MUSEU MUNICIPAL PARQUE DA BARONESA EM PELOTAS-RS
}

\author{
BONOTTO RUIVO, ROSEANA \\ Mestranda Prograu, Arquiteta e Urbanista \\ Universidade Federal de Pelotas \\ Rio Grande do Sul; Brasil \\ roseanabonotto@gmail.com
}

\author{
BALLERINI FERNANDES, TATIANE \\ Mestranda ConstruInova, Arquiteta e Urbanista \\ Universidade de São Paulo \\ São Paulo; Brasil \\ tatiane.ballerini@usp.br
}

\author{
DA SILVA TORRES, ARIELA \\ Doutora, Engenheira, Professora e Pesquisadora FAUrb \\ Universidade Federal de Pelotas \\ Rio Grande do Sul; Brasil \\ arielatorres@gmail.com
}

\section{RESUMO}

A cidade de Pelotas possui edificações tombadas a nível municipal, estadual e federal, além de muitas construções inventariadas datadas dos anos de 1800 a 1930, épocas importantes que contemplaram o desenvolvimento econômico regional por meio da cultura do charque e também do início da industrialização no município. Deste modo, Pelotas possui um importante conjunto histórico que deve ser estudado e preservado. Este artigo apresenta a análise das manifestações patológicas encontradas em uma edificação de interesse histórico do século XIX, localizada na cidade de Pelotas-RS, sendo ela o Museu Municipal Parque da Baronesa. O objetivo deste trabalho é, através do método de análise de Liechtenstein, identificar as manifestações patológicas encontradas nas fachadas externas dessa edificação por meio do levantamento de subsídios e do diagnóstico da situação, buscando determinar suas prováveis causas e a elaboração de um Mapa de Danos do edifício. Após a realização das análises, foi possível identificar que os principais danos encontrados na edificação foram o descolamento da pintura e do revestimento, sujidade, manchas de umidade, além de fissuras e trincas. Foi possível perceber que o Museu da Baronesa necessita intervenção periódica para combate a essas patologias. Dessa forma, é importante salientar a importância do conhecimento e mapeamento das manifestações patológicas existentes não só no objeto deste estudo mas em todo conjunto patrimonial de Pelotas, além do investimento financeiro para manutenção desses bens. Espera-se que este trabalho possa fomentar a manutenção de forma adequada e incentivar a preservação desses patrimônios históricos e culturais.

Palavras-chave: Manifestações patológicas, Patrimônio histórico, Patologia das construções, Tecnologia da Arquitetura

\begin{abstract}
Pelotas city has buildings at historical heritage list by municipal, state and federal levels, as well as many constructions from 1800 to 1930 that have been prohibited from being destroyed or mischaracterized. These periods were important times that contemplate regional economic development through the culture of jerked beef and also the beginning of industrialization of the municipality. From this way, Pelotas has an important historical set that must be studied and preserved. This paper presents an analysis of the pathological manifestations found at a historical building of nineteenth century, located in the city of Pelotas-RS, which is the Parque da Baronesa Municipal Museum. The objective of this paper is, through the analysis of Liechtenstein method, identify the pathological manifestations detected on the external facades of this construction, through the survey of subsidies and diagnosis of the situation, seeking to determine probable causes and a creation of a Damage Map building. After the analysis, it was possible to identify the main damages found at the building that was separation of paint and coating from its backing, dirt, humidity stains, as well as fissures and cracks. It was possible to notice that the Baronesa Museum needs periodic interventions to combat these pathologies. Thus, it is important to emphasize the importance of knowledge and mapping the pathological manifestations existing not important only for this study, but in the entire patrimony of Pelotas, in addition to the financial investment to maintain these assets. It is hoped that this work can promote the proper maintenance and the preservation of these historical and cultural heritage.

Keywords: Pathological manifestations, Historical heritage, Pathology of constructions, Architecture technology
\end{abstract}




\section{INTRODUÇÃO}

A cidade de Pelotas-RS é conhecida, entre outros aspectos, pelo seu patrimônio arquitetônico de interesse histórico, protegido por legislação municipal. Segundo Daltoé (2013), esse patrimônio edificado é datado principalmente do final do século XIX e início do XX. Nessa época, o país desenvolveu uma arquitetura cuja linguagem utilizava elementos variados originados de épocas e lugares distintos. Para Pelotas, esse ecletismo que ocorreu sobretudo nas fachadas das edificações, coincidiu com um momento histórico de apogeu econômico possibilitado pela fabricação do charque. Esse passado permitiu que na cidade houvesse o desenvolvimento de um número considerável de construções de valor artístico e histórico. Hoje, o município possui construções tombadas em nível municipal, estadual e federal, além de 1300 inventariadas (IPHAN, 2018).

Os prédios de interesse histórico fazem parte dos bens materiais que compõem o Patrimônio Ambiental Urbano. Se por um lado existem edificações que atravessam os séculos testemunhando bom gosto e técnica de bem construir, de outro, encontram-se edificações que chocam pela forma com que se degradam em um curto espaço de tempo. $\mathrm{O}$ controle de qualidade nas várias etapas do processo construtivo, como planejamento, projeto, seleção de materiais, execução da obra e uso da mesma são requisitos essenciais para a durabilidade de uma edificação (PERES, 2001).

De acordo com Figueiredo Junior (2017), a palavra Patologia é oriunda da linguagem grega, onde Páthos significa doença e Lógos, estudo. A terminologia citada é usada em diversas áreas da ciência para designar o estudo de anomalias ou problemas. A arquitetura e a engenharia estudam as anomalias de uma edificação utilizando-se de métodos para a identificação, descrição e determinação dos agentes patológicos que estão causando danos à edificação. As manifestações patológicas, por outro lado, podem ser definidas como sendo o conjunto de sintomas de uma edificação que indicam a deterioração de seus materiais ou componentes. O mapeamento das mesmas consiste no levantamento dos pontos que se apresentam degradados para gerar uma representação gráfica e escrita, formando o chamado mapa de danos (PASQUALOTTO, 2012).

Segundo Pereira (2012), os problemas patológicos em edificações, que apresentam manifestações externas, são problemas evolutivos que tendem a se agravar com o tempo, porém pode-se compreender a natureza, a origem e os mecanismos dos fenômenos envolvidos, o que possibilita a determinação das prováveis consequências de tais problemas. Para MACEDO (2016a), o método de maior eficácia e simples aplicação na detecção, levantamento e representação de danos e manifestações patológicas é a elaboração de um mapa de danos.

O mapa de danos permite a caracterização de diversos níveis de degradação do edifício através da representação gráfica e fotográfica do mesmo, tornando possível o conhecimento sobre as alterações estruturais e funcionais dos materiais, nas técnicas, nos sistemas e nos componentes construtivos (TINOCO, 2009). Além disso, os mapas de danos são instrumentos eficazes de auxílio tanto para o planejamento das diretrizes projetuais de restauro/conservação e das previsões orçamentárias, como podem também instruir ações de monitoramento preventivo para garantir a boa conservação dos artefatos no tempo (ANDRADE e HENRIQUE, 2012).

Macedo (2016b), desenvolveu uma pesquisa em que analisou as manifestações patológias encontradas nas fachadas do Teatro Santa Isabel, edifício construído na segunda metade do século XIX, na cidade de Recife, Pernambuco, especificando os processos de degradação atuantes na edificação. O edifício analisado está situado em uma região Litorânea e banhada pelos Rios Capibaribe e Beberibe, sendo considerado Patrimônio Histórico e Artístico Nacional a partir do seu Tombamento pelo IPHAN em 1949. O mesmo passou por três reformas, tendo sido concluída a última em 2002. O trabalho desenvolvido pelo autor foi realizado através de uma metodologia de pesquisa exploratória, que envolveu pesquisa bibliográfica, entrevistas, análise documental, além de visitas ao Teatro, visando fotografar, assim como, identificar e classificar as manifestações patológicas presentes na fachada do mesmo. Em função da altura do edifício foi utilizado um drone, veículo aéreo não tripulado, para acesso à estrutura do edifício e à realização de imagens de alta resolução.

A partir dessas análises foram identificadas no estudo as principais patologias encontradas no Teatro Santa Isabel, sendo elas: descamação da pintura, descolamento da argamassa do reboco, manchas provenientes da infiltração por água da chuva, degradação mecânica, descolamento de material pétreo, fissuras nas platibandas, cristalização de sais solúveis nas fachadas e teto, desagregação da granulometria do lioz (rocha calcarea proveniente da região de Lisboa), manchas formadas através de dejetos de animais, gases veiculares, além de vandalismo. Os resultados das análises permitiram a elaboração de um Mapa de Danos das Fachadas, onde foram identificadas as manifestações patológicas existentes, sua origem e localização na fachada. Além disso, o Mapa de Danos do trabalho analisado contribuiu com a elaboração de diretrizes e a identificação de manifestações patológicas de forma mais detalhada, contribuindo com informações técnicas para futuras intervenções e o prolongamento da vida útil do edifício. 
Assim, este trabalho tem como objetivo realizar o mapeamento das manifestações patológicas encontradas nas fachadas externas do Museu Municipal Parque da Baronesa (MMPB), edificação construída no século XIX na cidade de PelotasRS. O edifício, considerado Patrimônio Histórico Nacional apresentou como forma de análise o método de Lichtenstein. Busca-se com este estudo, fornecer informações compatíveis que possam ser utilizadas num potencial processo de recuperação e restauro desse importante monumento histórico.

\section{OBJETO DE ESTUDO}

Em 2018, o Conjunto Histórico de Pelotas foi tombado em nível federal pelo IPHAN, no projeto apresentado em Brasília. Os Setores de Proteção correspondem às praças José Bonifácio, Coronel Pedro Osório, Piratinino de Almeida, Cipriano Barcelos e o Parque Dom Antônio Zattera, junto com a Charqueada São João e a Chácara da Baronesa. Esses bens apresentam valor histórico diretamente relacionados a, no mínimo, dois momentos de desenvolvimento econômico regional: o do charque (1800 a 1900) e o do início da industrialização (1900 a 1930) (IPHAN, 2018).

O Museu Municipal Parque da Baronesa (MMPB), objeto deste estudo, foi construído em estilo neoclássico no século XIX (Sanes, 2017) estando localizado na Avenida Domingos de Almeida, na cidade de Pelotas-RS (Figura 1). Segundo Costa (2010), o antigo Solar da Baronesa, adquirido na época pela família Antunes Maciel, apresenta $840 \mathrm{~m}^{2}$ de área construída, estando situado em um terreno de aproximadamente sete hectares, cercado por uma extensa área verde, uma gruta construída de pedras, um pequeno castelo (destinado a acolher os pássaros), uma casa de banho onde as mulheres da família se refrescavam no verão, um sobrado em estilo bangalô de 1935 e um chafariz.

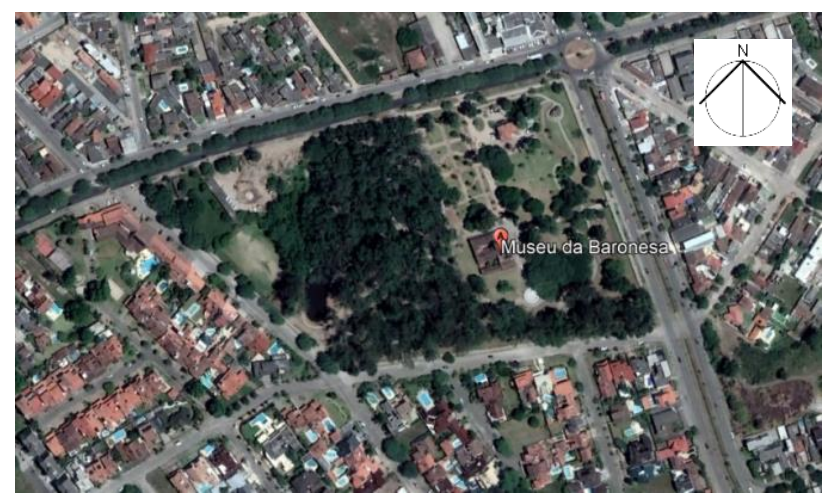

Figura 1: Localização do Museu da Baronesa.

Fonte: Google Earth.

A edificação do MMPB foi construída em alvenaria portante, com cobertura em telha cerâmica tipo capa e canal, contando com 61 janelas e 9 portas para a rua. O edifício é composto por um andar e mirante, com fachadas de arcos plenos e pátio interno, além de 24 cômodos e uma cobertura metálica no jardim da frente. Possui platibanda e estátuas com figuras humanas na cobertura de suas fachadas, além de estar elevada em relação ao terreno e ter vãos redondos com grades metálicas que permitem ventilação abaixo do pavimento térreo. A edificação possui pintura branca e salmão. A parte interior da edificação possui estuque, forro, piso e rodapé de madeira nos dormitórios e sala. Os banheiros e cozinha possuem piso cerâmico. As esquadrias são de madeira.

O edifício passou por três momentos: De 1863 a 1867, formação e pleno funcionamento como chácara, de 1887-1966 onde a propriedade se modernizou e seu uso se modificou ao longo do tempo e de 1966-1985 em que se deu a transição de espaço privado para público.

O Solar da Baronesa foi construído em 1863 (Figura 2), na mesma época que em que os filhos dos charqueadores começavam a estudar na Europa. O Barão Annibal Antunes Maciel recebeu esse título do Dom Pedro II por ter participado da emancipação dos escravos de Pelotas em 1884. Já a baronesa Amélia Hartley de Brito passava o inverno no Rio de Janeiro, para onde foram seguindo os membros da família após a morte do patriarca. A neta dos barões Déa Antunes Maciel foi a última da geração a ocupar a casa. (AACCMQ, 2015). 


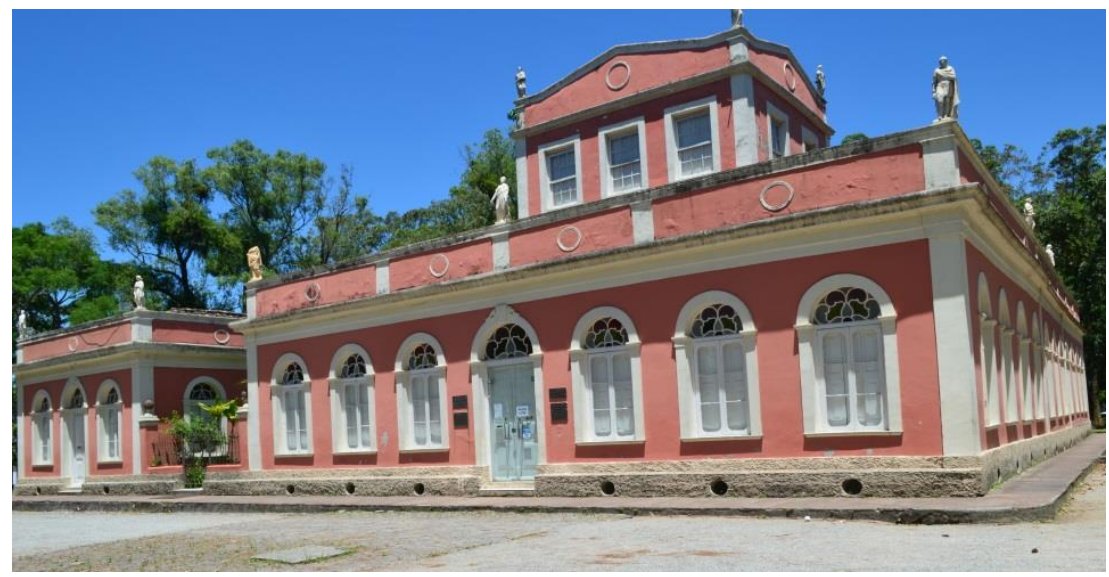

Figura 2: Fachada Nordeste do Museu da Baronesa.

Fonte: Os autores, 2018.

Em 1978, a residência e o parque em seu entorno foram doados pela família Antunes Maciel ao município de Pelotas, transformando-o em patrimônio histórico pertencente à cidade. Foram quatro anos de reforma promovidas pela Prefeitura, através de recursos do projeto CURA Baronesa, vinculado ao antigo Banco Nacional de Habitação (MONTONE, 2018) para transformar o antigo solar em museu.

Buscando preservar a história do Solar, em 25 de abril de 1982, foi inaugurado como Museu Municipal Parque da Baronesa um espaço cultural e de acesso ao público, que conta em seu acervo com peças das coleções da família Antunes Maciel, de Adail Bento Costa, doações diversas da comunidade e uma coleção de Antonia Sampaio. Estas peças representam um pouco dos costumes e da maneira de viver das famílias abastadas do século XIX. Três anos depois o MMPB foi tombado como Patrimônio Histórico Municipal (COSTA, 2010).

Desde 2005, a Associação de Amigos do Museu da Baronesa (AMBAR), uma entidade sem fins lucrativos, vem promovendo uma série de reparos pontuais como conserto de goteiras, reboco e pintura externa e interna, através de recursos arrecadados pela mesma e com auxílio da prefeitura. Ver situação atual da edificação na Figura 3. Os reparos seguem até os dias atuais (2019), onde a mesma associação foi responsável pela reforma do telhado, como limpeza entre os forros e as telhas, tratamento pontual para descupinização do mesmo, substituição de madeiramento apodrecido, substituição de telhas quebradas e colocação de manta onde havia goteiras (MONTONE, 2018).

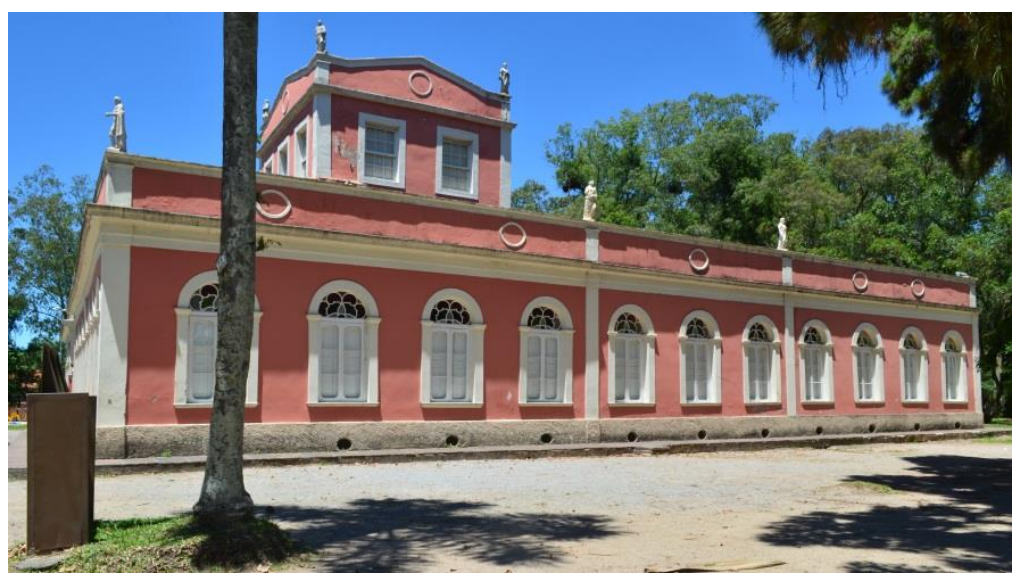

Figura 3: Fachada Noroeste do Museu da Baronesa.

Fonte: Os autores, 2018.

Outros importantes acontecimentos foram o Tombamento em Nível Federal pelo IPHAN (2018), com a finalidade de promover o acesso à obtenção de recursos para preservação do mesmo e a classificação do projeto "Visibilidade do negro no discurso do Museu da Baronesa”, em 25 lugar dentre 28 propostas (Prefeitura de Pelotas, 2018).

Em trabalho realizado por Montone (2018), observa-se que a edificação passou por reformas ao longo anos. Até a década de 1930 foram realizadas as maiores reformas na residência, onde além da conservação relativa ao desgaste dos materiais, infestações de insetos, umidade e goteiras, por exemplo, nessa época a habitação sofreu as maiores mudanças 
em seu interior e recebeu instalações que a modernizaram, como a instalação de azulejos, reformas na cozinha e quartos. No ano de 1960, foram realizados serviços de toda ordem para preservação da moradia, sobretudo instalações elétricas, de água, esgoto e consertos no telhado. Em 1979, já pertencente ao poder público, depois de experimentar um período de declínio (1966-1978) após a morte de Sinhá, iniciou-se um projeto de restauro da construção, que passou de moradia a Museu. Os itens mais significativos previstos nesse projeto foram à substituição da cobertura, do forro de madeira tipo saia e camisa, do reboco e do assoalho em tábua corrida; à execução de cinta de amarração em todas as paredes existentes, para receber a cobertura, instalações hidráulicas e elétricas, recuperação das esquadrias e da escada de madeira, além de pintura externa e interna. $\mathrm{O}$ memorial do projeto sugeria que as substituições deveriam atender às características originais. Entretanto, o modelo das janelas do entorno do algibe, da sala de almoço e da sala de jantar (salão de honra) foi modificado; as janelas do hall (internas) e o para-vento foram retirados.

Segundo a autora, durante o período das intervenções municipais, em que houve a mudança da função da edificação, muitas perdas nas características construtivas foram ocasionadas, principalmente devido a dificuldade, em termos de informações, de como lidar com edificações de caráter histórico. No tocante a este trabalho, este fato só reforça a importância do conhecimento das manifestações patológicas existentes na construção, como uma forma de auxiliar a preservação desses patrimônios.

Em relação ao histórico das manifestações patológicas existentes na construção, as mesmas já apareciam descritas em correspondências que tratavam do cotidiano entre a Baronesa Amélia Antunes Maciel e sua filha Amélia (D. Sinhá) no ano 1916, em que a primeira destaca a presença de sais e o aparecimento de manchas nas paredes em função da umidade (ACERVO MMPB).

"Para o quarto, são precisos 15 peças de papel de parede, e 1 de barra, si esta tiver 6 tiras; sendo de menos calcularás. Quanto à não levar bastidores, diz elle, ser impossível, pois as parêdes estão $\mathrm{mt}^{\mathrm{o}}$. salitradas, e a humidade mancha tudo (...) A humidade das parêdes, estraga tudo em pouco tempo". (Carta enviada por Amélia Antunes Maciel para a filha, em 30 de setembro de 1916)

Em outra carta do mesmo ano, é descrita a caiação das paredes externas e o surgimento de manchas nas paredes rapidamente.

\begin{abstract}
"Estou mandando caiar a casa por fóra, mas infelisme. As parêdes são tão salitradas, que em seguida a caiação, vão apparecendo as manchas. O mal está no tijolo, que parece ter sido fabricado com agua salitrada. Mas enfim, fica ao menos com cara de lavada, e portanto com melhor aparencia (...)". (Carta enviada por Amélia Antunes Maciel para a filha, em 06 de dezembro de 1916)
\end{abstract}

O conhecimento do histórico da construção é uma fonte importante para o diagnóstico da origem das manifestações patológicas presentes na edificação, sendo um instrumento fundamental para alcance dos resultados deste trabalho. A análise destas cartas e material que registraram as intervenções feitas ao longo dos anos nos traz subsídio para encontrar as possíveis das manifestações patológicas.

\title{
3. MÉTODO
}

Este trabalho foi realizado através do método de análise desenvolvido por Lichtenstein em 1986, levando em consideração as seguintes etapas de avaliação de edificações:

a) Revisão de Literatura referente ao tema manifestações patológicas em edificações, tendo como foco principal a análise de patologias em edificações de caráter histórico.

b) Levantamento de subsídios, realizado através de vistórias nas edificações em estudo, com o intuito de dectar a presença ou não de manifestações patológicas. As mesmas foram avaliadas por meio dos sentidos humanos, registro fotográfico, entrevistas e levantamento de informações dos projetos arquitetônicos.

c) Diagnóstico da situação, por meio da determinação das prováveis causas das manifestações identificadas. Para realização desta etapa, foram realizadas vistorias nas fachadas externas (foco deste trabalho), mas também nas fachadas internas com o objetivo de averiguar se alguma ocorrência existente no lado externo poderia ser derivado de problemas internos. 
d) Elaboração do Mapa de Danos do Museu Municipal Parque da Baronesa, através de documentos gráficos e fotográficos que mostram os danos nas fachadas externas dessa edificação, visando documentar as manifestações patológicas encontradas e o estado de preservação do edifício. Para desenvolvimento dos Mapas de Danos, após levantamento fotográfico e diagnóstico das patologias, as fachadas foram desenhadas em arquivo $\mathrm{CAD}$, tendo suas manifestações patológicas mapeadas no mesmo arquivo de acordo com o levantamento in loco.

Foram levantadas as manifestações patológicas existentes nas fachadas noroeste, nordeste, sudeste e sudoeste do Museu da Baronesa, conforme Figura 4.

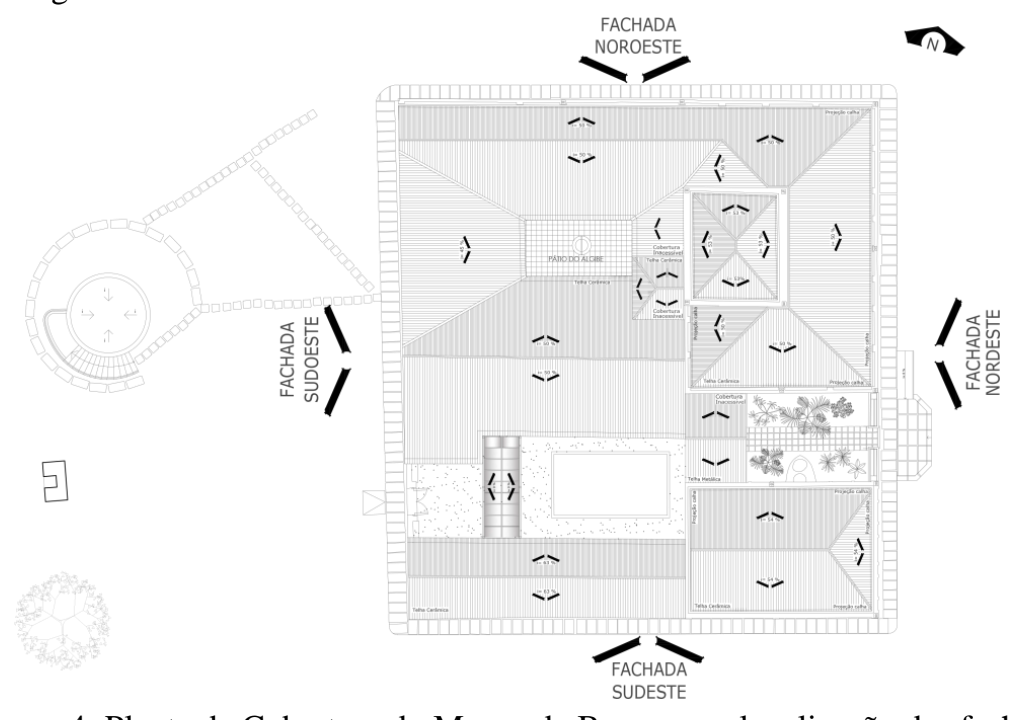

Figura 4: Planta de Cobertura do Museu da Baronesa e localização das fachadas.

Fonte: Os autores.

\section{RESULTADOS}

A partir do levantamento de subsídios e do diagnóstico da situação realizados através de visitas in loco, entrevistas com os responsáveis pelo edifício e fotografias das manifestações patológicas encontradas no Museu Municipal Parque da Baronesa, exemplificadas conforme figura 5. Foram desenvolvidos Mapas de Danos das fachadas da edifícação com o intuito de mapear essas informações e assim avaliar o estado de conservação do edifício em estudo. Para tornar isso possível, a realização do diagnóstico das manifestações patológicas também se deu através de inspeções realizadas no interior do edifício com foco nas fachadas internas, com a intenção de avaliar se alguma patologia presente nas fachadas externas poderia ser proveniente de danos internos. As avaliações tanto das fachadas externas quanto internas, juntamente com a uma investigação sobre o histórico da construção e de seu processo de deterioração permitiram conhecer a origem das principais manifestações patológicas presentes nas fachadas externas do Museu.

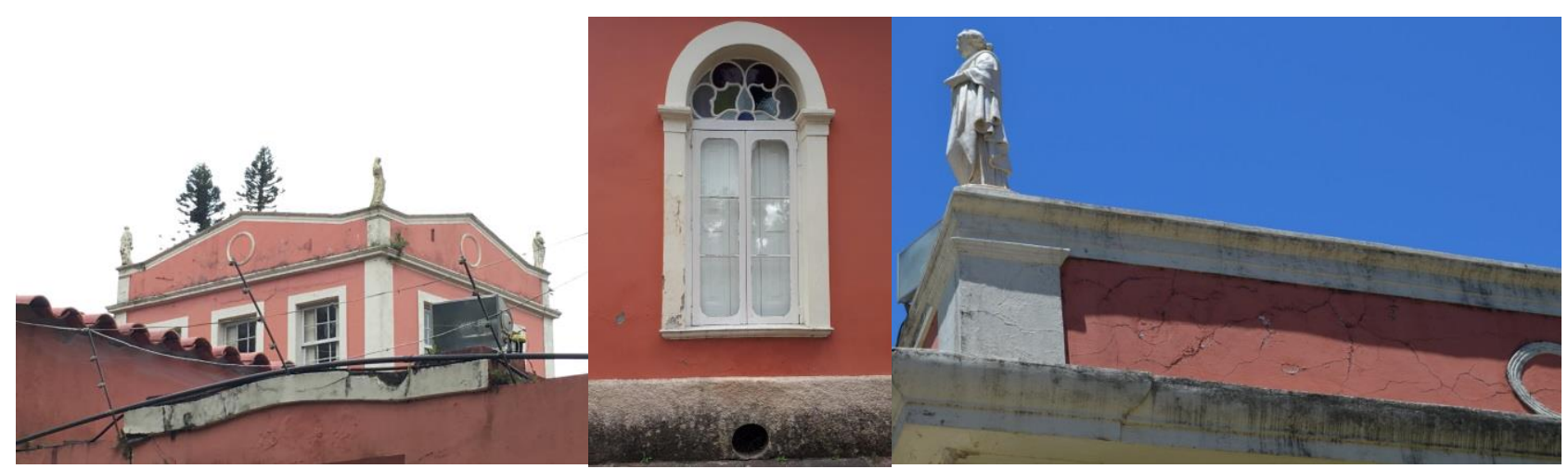

Figura 5: Detalhes das Manifestações Patológicasa do Museu da Baronesa.

Fonte: Os autores, 2018.

O mapeamento das manifestações patológicas existentes nas fachadas noroeste, nordeste, sudeste e sudoeste, foram representados conforme figuras 7, 9, 11 e 13. Por meio delas é possível identificar que na fachada nordeste as principais 
patologias encontradas foram o descolamento da película de tinta, sujidade, descolamento do revestimento, fissuras e manchas de umidade (Ver Figuras 6 e 7).

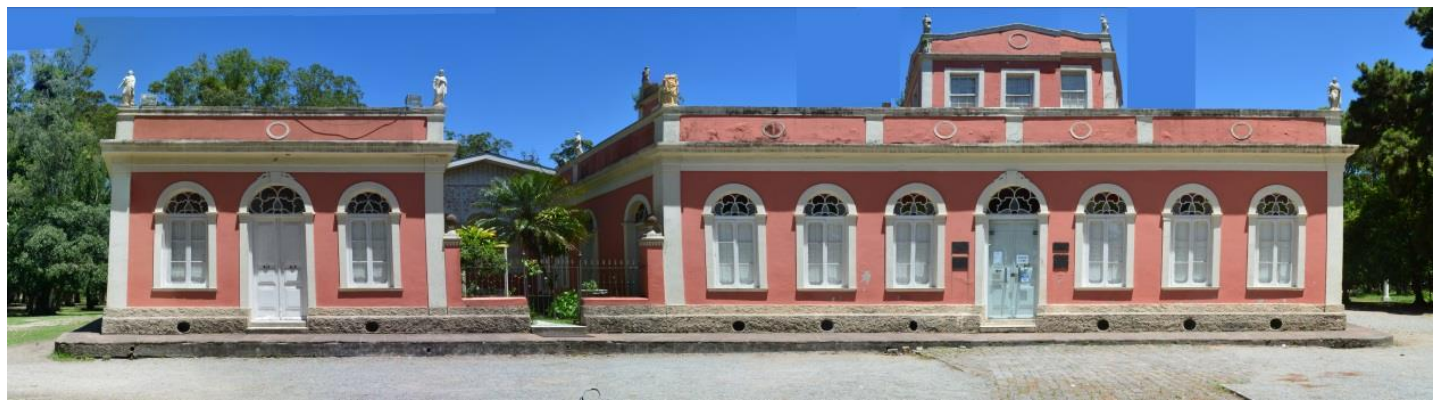

Figura 6: Fotomontagem da Fachada Nordeste.

Fonte: Os autores.
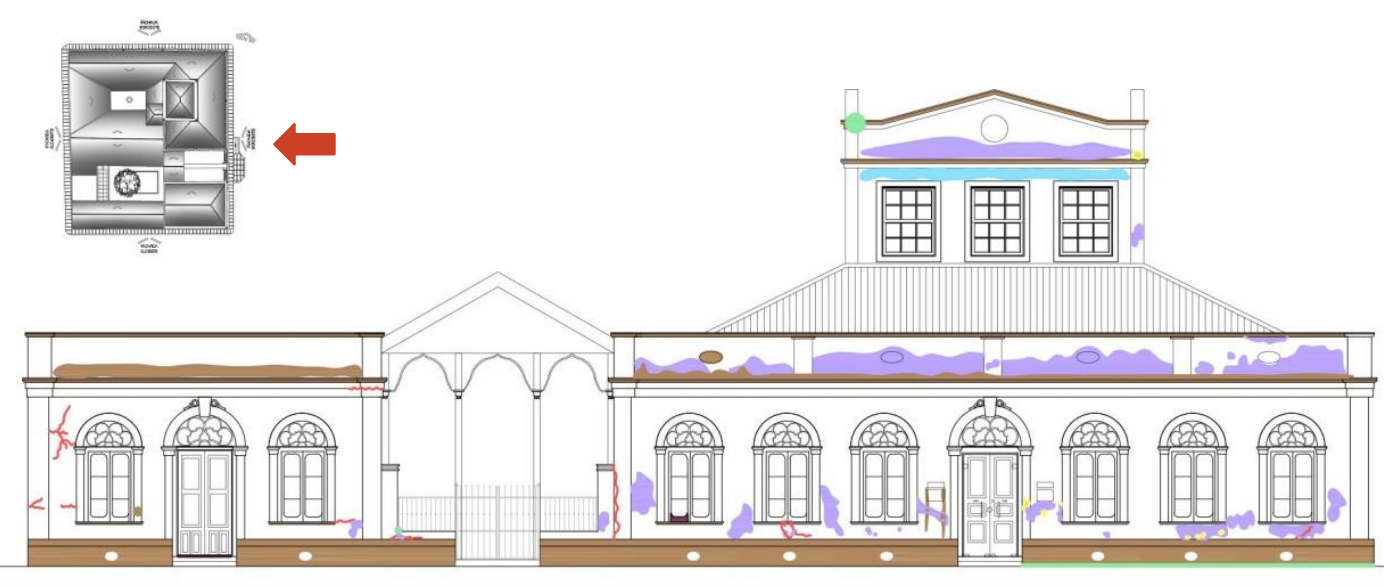

FISSURAS, TRINCAS, RACHADURAS

EFLORESCENCIA

DESCOLAMENTO DE REVESTIMENTO

\begin{abstract}
DESCOLAMENTO DA PINTURA
MANCHAS DE MOFO, BOLOR

MANCHAS DE UMIDADE
\end{abstract}

SUIIDADE CORROSÃO

VEGETAÇÃO

Figura 7: Fachada Nordeste do Museu da Baronesa e localização da fachada em Planta. Análise de Manifestações Patológicas e legenda. Fonte: Os autores.

Já na fachada noroeste destacou-se a presença do descolamento da película de tinta e em alguns pontos do revestimento, manchas de umidade proveniente tanto por infiltração de água do solo, quanto por água da chuva, fissuras e trinca, além de sujidade (Figura 8 e 9).

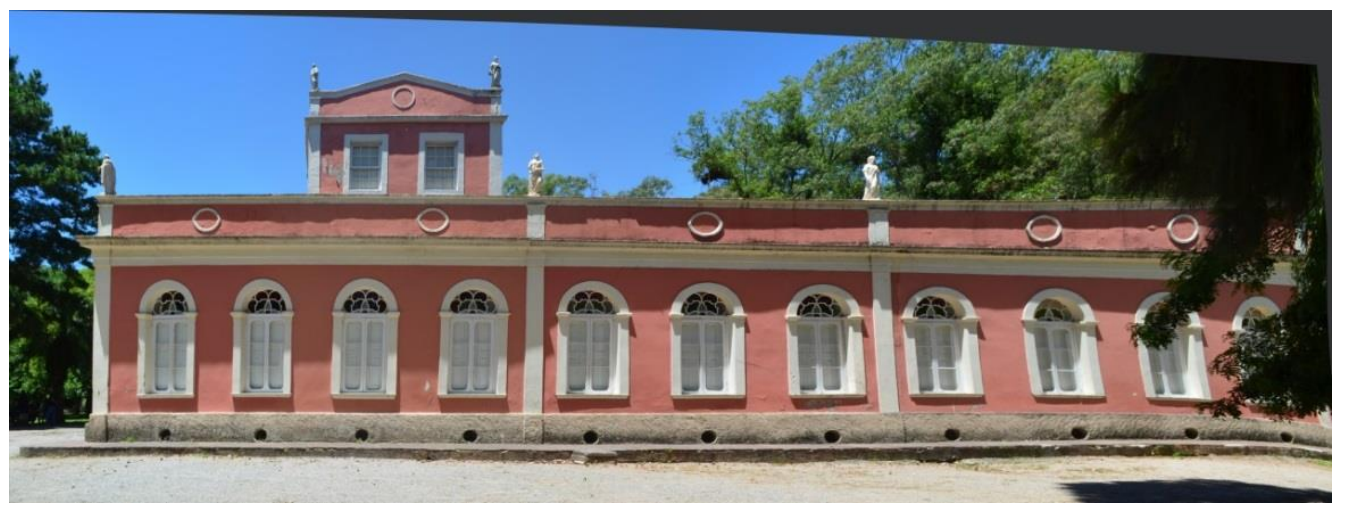

Figura 8: Fotomontagem da Fachada Noroeste do Museu da Boronesa.

Fonte: Os autores 


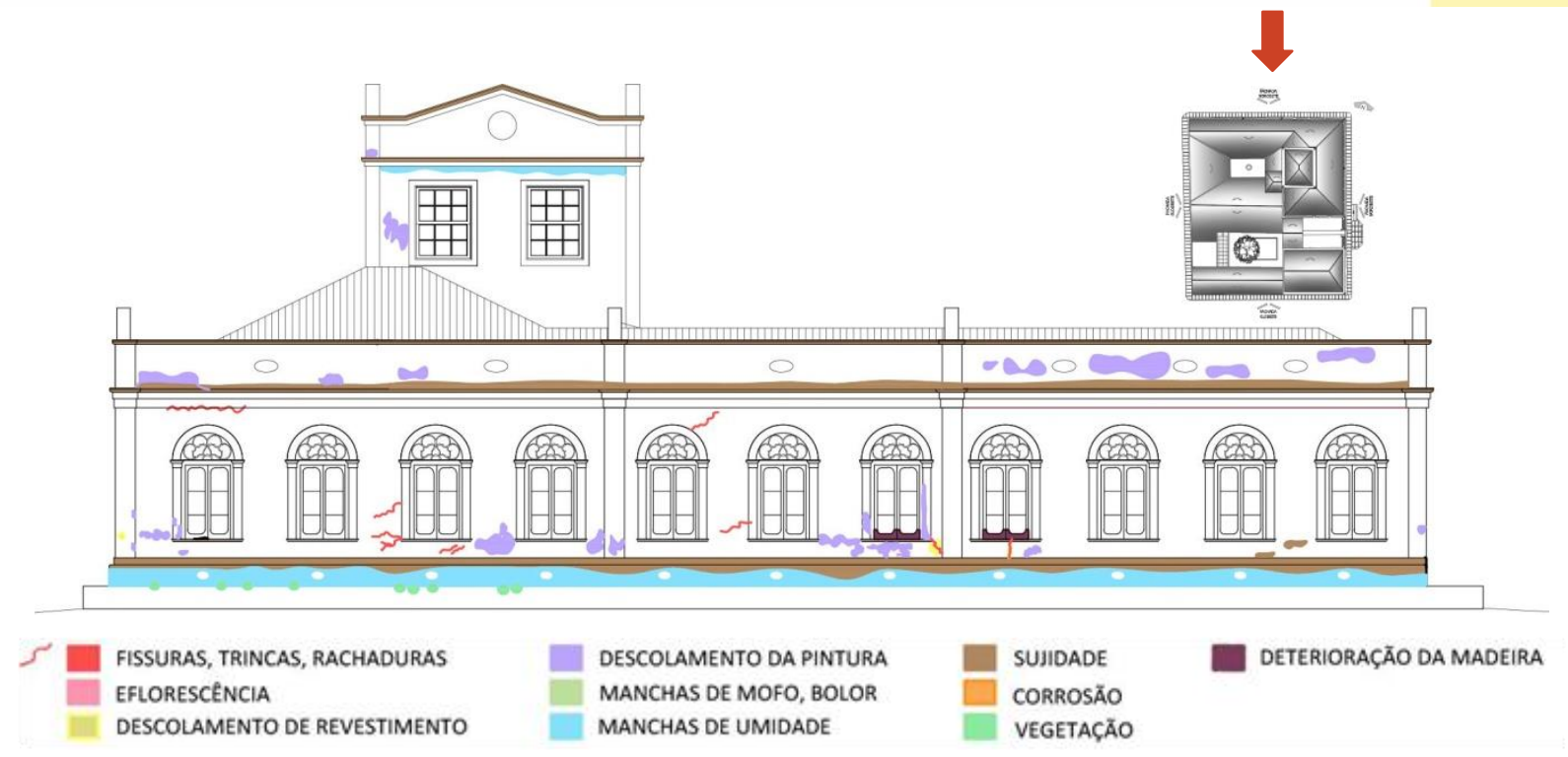

Figura 9: Fachada Noroeste do Museu da Baronesa e localização da fachada em planta.

Análise de Manifestações Patológicas e legenda.

Fonte: Os autores.

A fachada sudoeste apresentou majoritariamente sujidade, presença de fissuras e trincas com vegetação, manchas de umidade, descolamento da pintura e do revestimento (Figuras 10 e 11), enquanto a fachada Sudeste apresentou marcas de sujidade, manchas de umidade e descolamento da pintura (Figuras 12 e 13).

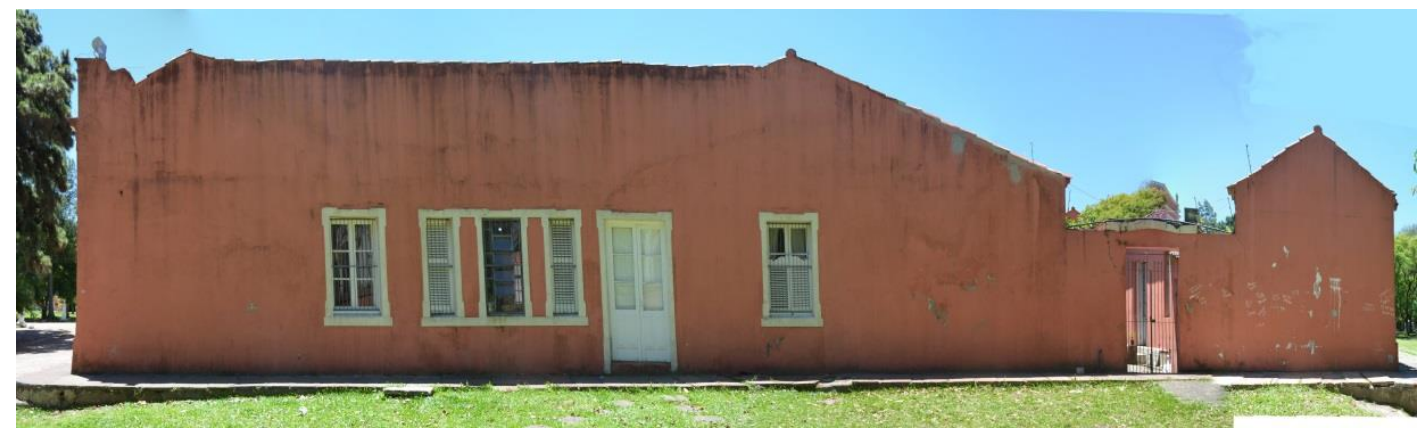

Figura 10: Fotomontagem da Fachada Sudoeste do Museu da Boronesa. Fonte: Os autores.
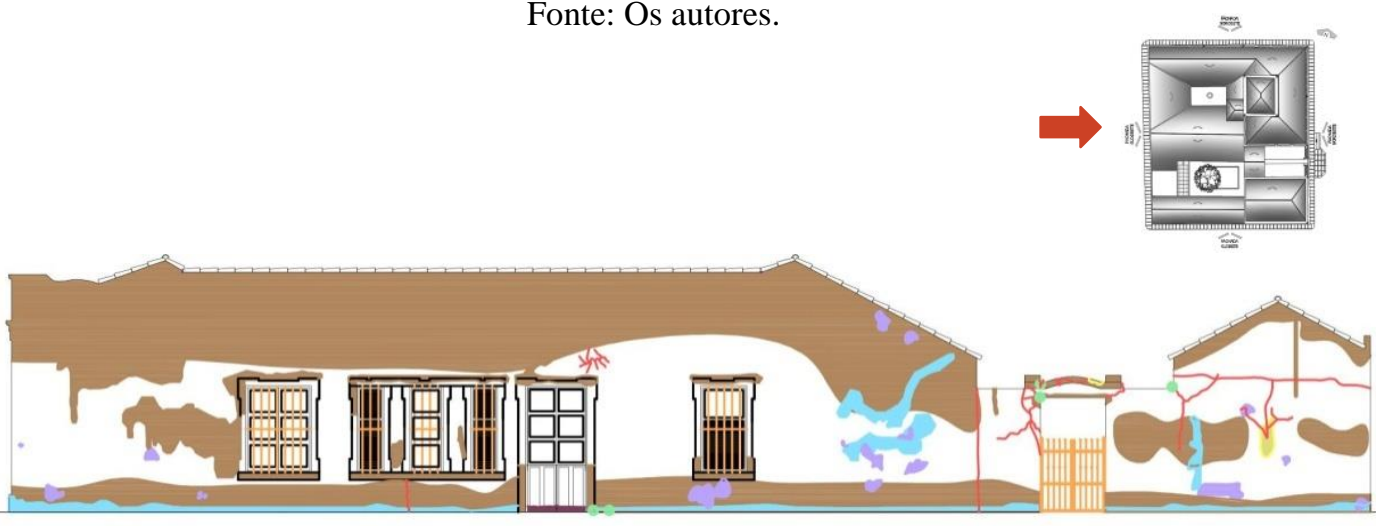

FISSURAS, TRINCAS, RACHADURAS EFLORESCENNCIA

DESCOLAMENTO DE REVESTIMENTO
DESCOLAMENTO DA PINTURA MANCHAS DE MOFO, BOLOR MANCHAS DE UMIDADE
SUIIDADE CORROSÃO VEGETAÇÃO

Figura 11: Fachada Sudoeste e localização da fachada em Planta do Museu da Baronesa. Análise de Manifestações Patológicas e legenda.

Fonte: Os autores. 


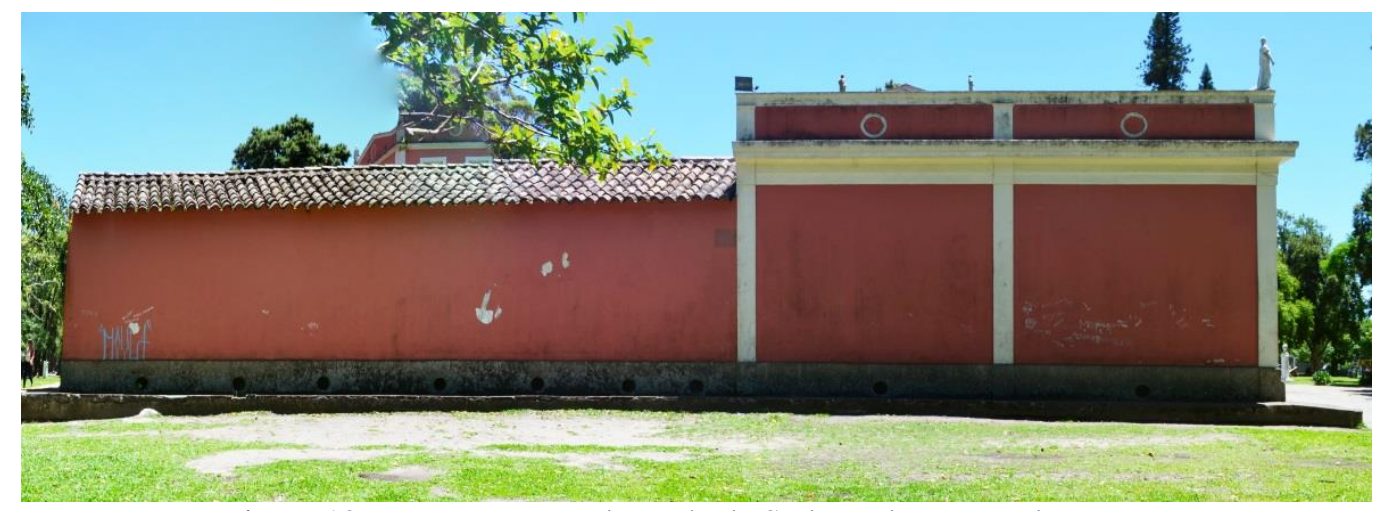

Figura 12: Fotomontagem da Fachada Sudeste do Museu da Boronesa.

Fonte: Os autores.

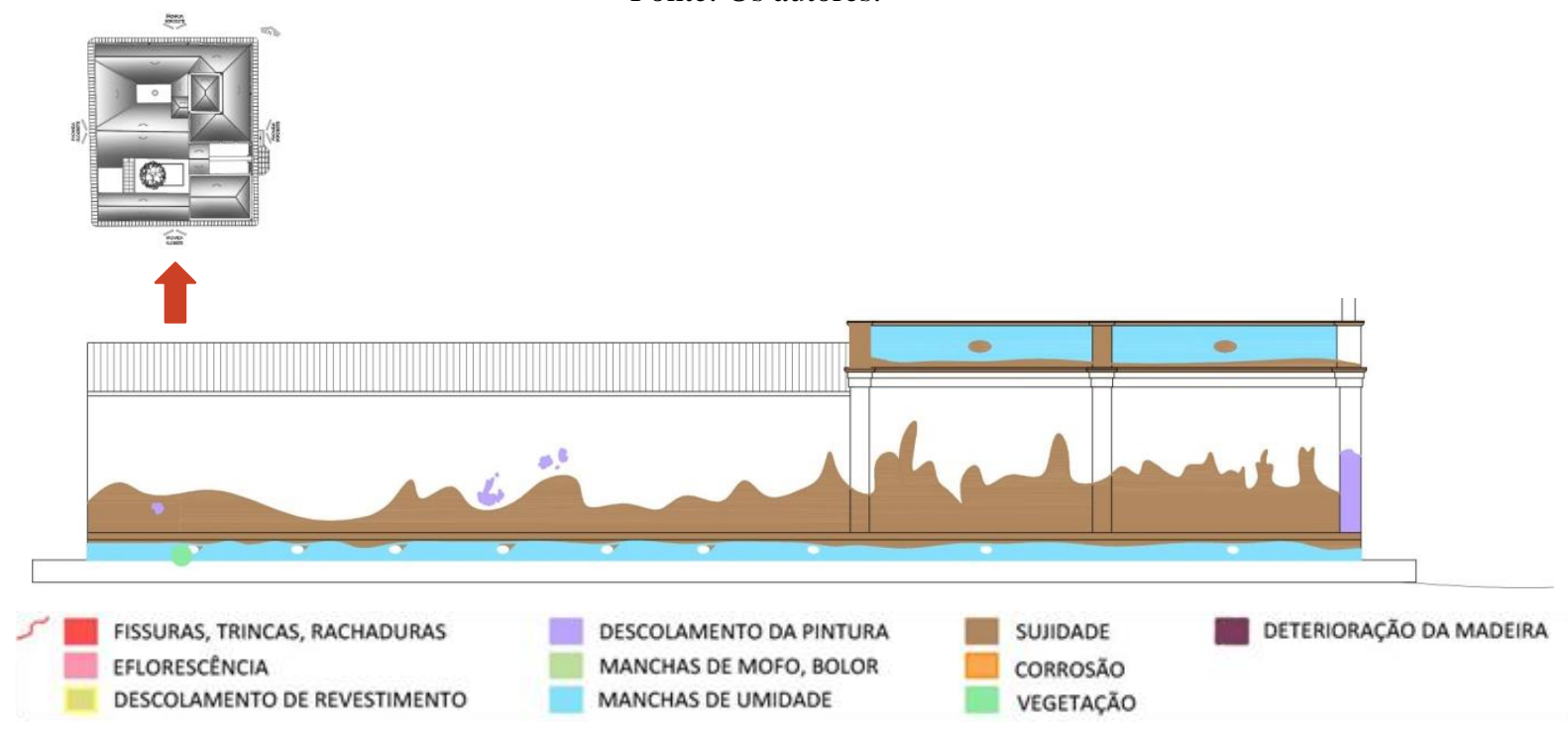

Figura 13: Fachada Sudeste do Museu da Baronesa. Análise de Manifestações Patológicas e legenda.

Fonte: Os autores.

Dessa forma, como resultados foi possível perceber que as principais ocorrências encontradas se dão pela presença de umidade, seja por infiltração por água das chuvas ou por água do solo, sujidade, além de problemas de manutenção. $\mathrm{O}$ Museu foi construído em um terreno onde o lençol freático está muito próximo à superfície, fomentando dessa maneira a ocorrência de manchas de umidade na base da edificação. Além disso, a contribuição da umidade é maior nos danos externos em função da construção estar localizada em uma cidade com umidade relativa bastante elevada, Pelotas-RS apresenta 83,6\% de umidade relativa anual (INMET) e por estar inserida dentro de extensa área verde. A vegetação contribui também para uma maior área úmida com a transpiração das folhas e também com a sombra gerada pelas mesmas, reduzindo a incidência solar no entorno da edificação.

Durante as visitas in loco, verificou-se a presença de danos na cobertura do edifício que permitem que a infiltração por água da chuva seja bastante acentuada no interior do edifício. Esses danos influenciaram o aparecimento de manchas de umidade na fachada, sendo possível notar o surgimento das mesmas imediatamente abaixo da estrutura da cobertura e nas platibandas, sendo uma das causas possíveis para o descolocamento da pintura nesses pontos. Observou-se que além do descolamento da pintura nas platibandas, o mesmo também ocorre em pontos próximos as janelas da edificação, podendo esse ser um problema relacionado a manutenção do edifício. Soma-se a isso a presença da sujidade em diferentes regiões das fachadas, seja pelo contato da água com a sujeira, nos casos identificados na base do edifício, nas cornijas ou pela ausência de beiral, como acontece na fachada sudoeste e em parte da sudeste. Além da influência do meio para a sujidade do edifício, também foi possível observar a presença de vandalismo através de marcas de pichação nas fachadas orientadas para o sul. 
Em relação a problemas relacionados a fissuras e trincas esses foram bastante pontuais, aparecendo em pontos das fachadas noroeste e nordeste, e principalmente, na sudoeste. Essas situações podem ter ocorrido por diferença térmica no comportamento entre diferentes materiais, como alvenarias e aberturas (fissuras próximas às esquadrias), condição com destaque nas fachadas noroeste e nordeste.

As fissuras e trincas podem ter ocorrido em função de deformações higrotérmicas (tração e retração ocasionadas pela ação da temperatura adicionadas à umidade) da alvenaria, retração de revestimentos, movimentação ou acomodação da estrutura.

No que diz respeito ao fissuramento na diagonal próximo principalmente aos vértices das esquadrias, esses podem ter origem devido ao subdimensionamento de vergas e contravergas ou mesmo a inexistência das mesmas, o que contribui para a sobrecarga da estrutura e o consequente fissuramento. As fissuras nos peitoris também podem ter sido ocasionadas por flexão negativa. Percebeu-se a presença de fissuras próximas a descontinuidades de elementos construtivos, principalmente na união entre paredes, caso das fachadas nordeste e sudoeste, onde fissuras verticais aparecem no encontro dos tijolos de alvenaria estrutural em diferentes direções nos limites da edificação. Segundo Thomaz (1989) as fissuras por sobrecarga em torno de aberturas ocorrem em paredes de alvenaria descontínuas, com uma ou mais aberturas, submetidas a carregamentos de compressão excessivos e têm como característica a formação de fissuras a partir dos vértices das aberturas. Essas fissuras podem estar relacionadas à deficiência ou ausência de amarração na parede de alvenaria, como também por uma espessura maior de argamassa de assentamento no encontro dos tijolos da alvenaria. Normalmente a fissura por deficiência de amarração pode estar associada a variações térmicas, retração e recalques. Deste modo, a movimentação causada por estes fatores encontra um ponto frágil e ocorre o fissuramento.

Na proximidade dos elementos, pode ocorrer a movimentação da alvenaria provocada pela dilatação e contração térmica dos tijolos nas paredes, condição que ocorre principalmente quando não foram previstas juntas de dilatação. Na fachada sudoeste, região à direita da mesma, a presença de fissura é ocasionada provavelmente pela ancoragem do forro e da cobertura diretamente na alvenaria. Essa situação gera movimentações que podem ocorrer por dilatação térmica ou movimentação higróscópica da madeira.

Assim, pode-se avaliar que por meio do metódo utilizado foi possível conhecer e mapear as manifestações patológicas existentes no Museu Municipal Parque da Baronesa, contribuindo para que soluções de reparo possam ocorrer de forma mais adequada e eficiente, além de colaborar com a preservação desse e de outros monumentos históricos.

\section{CONCLUSÃO}

Sendo o Museu Municipal Parque da Baronesa um valioso exemplar do patrimônio histórico de Pelotas-RS, buscou-se neste trabalho caracterizar os danos encontrados em suas fachadas. O levantamento de dados realizados através da inspeção in loco da edificação permitiu a elaboração do mapeamento das manifestações patológicas encontradas nas fachadas externas e a elaboração de mapas de danos, fornecendo informações compatíveis e que podem ser utilizadas num potencial processo de recuperação das mesmas.

Os resultados deste trabalho evidenciaram a presença de danos superficiais existentes nas fachadas do Museu da Baronesa, onde ficou evidente a grande quantidade de manifestações patológicas como descolamento da pintura, sujidade, manchas de umidade, descolamento do revestimento e presença de trincas e fissuras. Em sua maioria, pode-se identificar que as principais patologias encontradas estão relacionadas a problemas de umidade e a precária manutenção do edifício. Entretato, se por um lado os danos externos são pequenos, a parte interna do Museu da Baronesa apresenta um nível elevado de degradação, principalmente devidos aos danos da cobertura, situação que se reflete no surgimento de manifestações patológicas também nas fachadas externas do edifício.

O fato da edificação ter passado ao poder municipal apenas no final da década de 70, e anteriormente ter já passado por inúmeras reformas que culminaram na perda de algumas de suas características originais, além da burocratização para o recebimento de repasses financeiros do município que contribuem para a deterioração desse patrimônio. Embora o Museu tenha auxílio de uma instituição filantrópica, a mesma não apresenta aporte financeiro suficiente para mantê-lo. O método de análise das manifestações patológicas se mostrou um importante instrumento para caracterização dos danos encontrados na edificação e um meio para avaliação de possíveis formas de reparo e prevenção de novos problemas.

Assim, espera-se que os resultados deste trabalho contribuam na recuperação e preservação da edificação em estudo, já que a ausência de manutenções pode vir a se tornar fator responsável pelo aparecimento de problemas e manifestações 
patológicas de maior gravidade, implicando, potencialmente em grandes gastos e, dependendo da situação, podendo levar até mesmo ao comprometimento estrutural e visual desse Patrimônio Histórico e Cultural.

\section{AGRADECIMENTOS}

Um agradecimento especial ao PROGRAU, Programa de Pós Graduação em Arquitetura e Urbanismo da Universidade Federal de Pelotas que deu suporte à confecção desta pesquisa.

\section{REFERÊNCIAS}

AACCMQ. Associação dos Amigos Casa de Cultura Mario Quintana. Matéria: Associação de Amigos do Museu da Baronesa fortalece instituição pelotense. Publicado em 15/06/2015. Disponível em: http://www.aaccmq.com.br/site/?p=2291. Acesso em: 05/11/2019

ANDRADE, R. T; HENRIQUE, R. C. Sistema normativo para mapa de danos de edifícios históricos aplicado à lidgerwood manufacturing company de campinas. Campinas, 2012. Disponível em: <portal.iphan.gov.br/ckfinder/arquivos>. Acesso em: 12/06/2018.

CHEVALIER, Ceres. Vida e obra de José Isella: arquitetura em Pelotas na segunda metade do século XIX. Dissertação - Universidade Federal do Rio Grande do Sul, 2002. 194-196p.

COSTA, N.S. "Entendendo, Aplicando e Conhecendo": A educação no Museu Municipal Parque da Baronesa, Pelotas/RS, 2005-2009. Monografia - Universidade Federal de Pelotas - Curso de Bacharelado em Museologia. Pelotas, 2010. 32-33-34-35p.

DALTOÉ, Guilherme. Arquitetura Eclética de Caetano Casaretto em Pelotas/RS. Revista Memória em Rede, Pelotas, v.3, n.8, Jan./Jun.2013 - ISSN- 2177-4129.

IPHAN. Pelotas (RS). Disponível em: <http://portal.iphan.gov.br/pagina/detalhes/281〉. Acesso em: 10 de novembro de 2018.

- $\quad$ http://portal.iphan.gov.br/pagina/detalhes/1764 Acesso em: 19 de dez. 2018

http://portal.iphan.gov.br/uploads/atas/88_reuniao_ordinaria_do_conselho_consultivo.pdf Acesso em: 19 de dez. 2018.

INMET. Instituto Nacional de Meteorologia. Disponível em: http://www.inmet.gov.br/. Acesso em 09/11/2019

MACEDO, Aureliano Amaro Ribeiro Souza de. Mapa de Dano das Fachadas do Teatro de Santa Isabel, Recife Pernambuco. Dissertação de Mestrado, apresentada ao Departamento de Engenharia Civil da Universidade Católica de Pernambuco. Recife, 2016.

MARQUES, G. G. Avaliação de Edificações: Diagnóstico de Manifestações Patológicas das Áreas Condominiais e Fachada Principal de Prédio Residencial em Porto Alegre/RS. Trabalho de Conclusão de Curso - Universidade Federal do Rio Grande do Sul - Curso de Engenharia Civil. Porto Alegre, 2009. 16-17p.

MOnTONE, C. A. Memórias de uma forma de morar: a Chácara da Baronesa, Pelotas, RS, Br. (1863-1985). Programa de Pós-Graduação em Memória Social e Patrimônio Cultural, UFPEL. Pelotas - RS, 2018. 183 p.

THOMAS, E. Trincas em edifícios: causas, prevenção e recuperação. São Paulo: PINI, 1989. 
PASQUALOTTO, Natália. Manifestações Patológicas em Edificação Histórica: Estudo no Prédio do Observatório Astronômico da UFRGS. Trabalho de Diplomação apresentado ao Departamento de Engenharia Civil da UFRGS, Porto Alegre, 2012, pg. 27. Disponível em: https://lume.ufrgs.br/handle/10183/65437 Acesso: 18 de dez. 18

PREFEITURA MUNICIPAL DE PELOTAS. Patrimônio Nacional: arquitetura pelotense é reconhecida pelo Iphan. 2018

PEREIRA, Luciana Manzoni. Avaliação das Patologias e da Bioterioração na Biblioteca Central da UFSM. Dissertação (Mestrado em Engenharia Civil e Ambiental), UFSM, 2012.

PERES, Rosilena Martins. Levantamento e Identificação de Manifestações Patológicas em Prédio Histórico - Um Estudo de Caso. Dissertação de Mestrado apresentada ao Programa de Pós-graduação em Engenharia Civil da UFRGS. Porto Alegre, 2001. Disponível em: https://lume.ufrgs.br/handle/10183/1582 Acesso: 19 de dez. 2018

SANES, F. A. Da sala de aula para o museu: um olhar para as visitas de grupos escolares ao Museu Municipal Parque da Baronesa. Trabalho de Conclusão de Curso - Universidade Federal de Pelotas - Curso de Licenciatura em História. Pelotas, 2017. 23-24-25p.

TINOCO, Jorge Eduardo Lucena. Mapa de Danos - Recomendações Básicas. Centro de Estudos Avançados da Conservação Integrada, CECI. Olinda, Pernambuco, 2009, v. 43 p. 23. 